\title{
Development, optimization, and in vitro evaluation of atorvastatin calcium and vinpocetine codelivery by solid lipid nanoparticles for cancer therapy
}

Rita R. Lala* (1) and Amol S. Shinde

\begin{abstract}
Background: The main objective of the present study was to formulate, optimize and characterize solid lipid nanoparticles (SLNs) loaded with Atorvastatin Calcium (ATS) and Vinpocetine (VIN) as a potential drug delivery system to improve its solubility and assess its anti-tumor activity on cell lines. The SLNs were formulated by emulsification with high speed homogenization followed by probe sonication. Central composite design was selected for optimization. Drug: lipid ratio, surfactant: co-surfactant ratio and homogenization speed were considered critical process parameters (CPP) to study the effects on critical quality attributes (CQA) of SLNs i.e. particle size, percent entrapment efficiency (\% EE) and percent drug loading (\% DL).

Results: The optimized (F3) SLNs formulations were characterized by transmission electron microscopy (TEM), Xray diffraction $(X-R D)$, in vitro drug release by dialysis bag method and stability studies. In vitro cell line studies were performed on HepG2, MCF 7 and melanoma B16 F10 cell line. The optimized F3 formulation showed a particle size of $323 \pm 6 \mathrm{~nm}$, poly dispersity index (PDI) $0.333 \pm 0.02$, Zeta potential (ZP) $-30.4 \pm 0.66$ emv with \% EE 64.69 \pm 1.1 ; $65.98 \pm 0.91$ of ATS and VIN respectively. In vitro release (F3) of ATS and VIN in PBS pH 7.4 was found to be $89.45 \%$ and $91.86 \%$, respectively, up to $24 \mathrm{~h}$.
\end{abstract}

Conclusions: In vitro cell line study demonstrated that SLNs enhanced the anti-cancer activity of ATS, VIN on all the stated cell lines when compared with free drugs. Combination index (CI) for HEPG2 was 0.8, which signified synergistic effect. The results exhibited that SLNs is effective, stable and had enhanced activity against HepG2, MCF 7 and melanoma B16 F10 cell lines.

Keywords: SLNs, Co-delivery, Optimization, Cell line

\section{Background}

Statins are a class of drugs which are generally used for hyperlipidemia. Nowadays, it has been evidenced that they act as chemo preventive agents for several types of cancers alone or in combination with anti-cancer drugs [1]. They display varied types of mechanisms such as

*Correspondence: rr.lala@kmkcp.edu.in

Department of Pharmaceutics, Principal K. M. Kundnani College of Pharmacy, Mumbai 400005, India inhibition of proliferation and induction of apoptosis, anti -invasion effect, anti-migratory effect, thus overcoming the classic chemotherapeutic drug resistance. Statins inhibit the production of sterols as cholesterol, which is essential for membranes integrity and also simultaneously, block the isoprenylation of key oncoproteins that regulate proliferation, migration, invasion, cell cycle and cell fate $[2,3]$. Single therapy with statins is not sufficient to suppress the tumor growth and hence it is required to be administered with other chemotherapeutic agents to augment its synergistic activity and improve 
its therapeutic activity [3]. VIN inhibits cell proliferation, survival and migration in vitro thereby suppressing tumor growth in vivo. Therefore, we proposed to codeliver ATS and VIN in combination to achieve synergistic activity of both drugs [4].

As a combination therapy, multi-drugs are used which ameliorates the synergistic effect against cancer and the dose of each drug candidate is also reduced. Thus, the dose dependent side effects are reduced, which improves patient compliance [5]. Hence, combinational therapy approach is used while treating the cancer.

SLNs are a promising drug delivery for cancer chemotherapy. SLNs are suitable for hydrophilic and hydrophobic drugs. There are a number of problems associated with cancer chemo therapy drugs like dose dependent side effects, normal tissue toxicity, poor specificity and targeting and also multi drug resistance (MDR). All these problems can be resolved by SLNs drug delivery [6]. SLNs for combinational drug delivery increase the bioavailability of the drug by reaching the target site and increasing the therapeutic efficacy, reducing the dosing frequency and avoiding erratic absorption of a drug [7].

In the preparation of SLNs, CPP is considered on the basis of composition and variables which influence the quality of SLNs. The concentration of lipids ratio, concentration of surfactant-co-surfactant, speed of homogenization, probe sonication time-these are some CPPs which influence the CQA like particle size, \% EE and drug loading. Thus, while designing and formulating SLNs these CPP factors are needed to be considered while developing stable formulation with high EE, drug loading and lesser particle size $[8,9]$.

ATS inhibits the Rho activation and reverts the metastatic phenotype of human cells [10]. It was proved that ATS show a cytotoxic effect on human T, B and myeloma tumor cells by promoting their apoptosis [11]. ATS and $\gamma$ tocotrienol showed strong action against colon cancer cells by arresting cell cycle and apoptosis [12]. ATS induced growth inhibition of human pancreatic cell lines (Panc-1 and MIA PaCa-2 cells) [13]. ATS has low oral bioavailability $(12 \%)$ due to it's poor aqueous solubility [14].

VIN a vasoactive Vinca alkaloid is used in the treatment of cerebral vascular disorders and cerebral degenerative diseases like Alzheimer's disease. VIN has low oral bioavailability (7\%) and undergoes first pass effect [15]. It has been demonstrated that VIN induces cell aptosis via mitochondrial pathway and anti-cancer activity [4].

The objective of this research study was to formulate, optimize, characterize and evaluate SLNs drug delivery for cancer therapy. In vitro cell line studies were investigated for the formulation to examine its effectiveness against cancer.

\section{Methods}

\section{Materials}

ATS was a gift from SRS Pharmaceuticals Pvt. Ltd. Mumbai and VIN was gifted by India Glycols, India. Precirol ATO5 and Labrasol were gifted by Gattefosse Pvt Ltd, Germany. Glycerol Monostearte (GMS) was supplied by Mohini Organic, Mumbai, and Polaxomer 188 by Signet Chemical Corporation Pvt Ltd. Mumbai. Tween 80 and Methanol were purchased from Loba Chemie and Merck, respectively. Other Chemicals and reagents were of AR grade from local suppliers.

\section{Screening of solid lipids}

Compritol 888 ATO, Precirol ATO 5, Emulcire, Gelucire, Cetyl palmitate, Stearic acid and GMS were selected as solid lipids for the study. $10 \mathrm{mg}$ drug was taken in test tube and 0.2 gm solid lipid incrementally added with continuous stirring. The test tube was heated in controlled temperature water bath kept at $80{ }^{\circ} \mathrm{C}$ or $5{ }^{\circ} \mathrm{C}$ above the melting point of the respective lipid. The amount of solid lipid was added incrementally till a clear solution was obtained. The quantity of lipid required to form clear solution was assessed. Individual studies were performed for ATS and VIN. The experiment was performed in triplicate.

\section{Screening of surfactant and co-surfactant}

Labrasol, Triton X100, Tween 20, Tween 80, Span 20, Span 80, Poloxamer 407 and Poloxamer 188 were selected as surfactants for the study. Excess amount of ATS and VIN were added to a known volume of surfactant $(2 \mathrm{ml})$, mixed to get saturated solution. A mechanical shaker was used for $24 \mathrm{~h}$ to dissolve the drug. The contents were then centrifuged at $10,000 \mathrm{rpm}$ for $15-20 \mathrm{~min}$. The contents of the supernatant saturated surfactant systems were diluted with methanol and analyzed by UV spectrophotometer. The individual studies were performed for ATS and VIN. The experiment was performed in triplicate.

\section{Screening of solid lipid ratio}

Individual drug solubility studies in each lipid are not explained here, but on the basis of highest solubility of drug in solid lipid, these were selected for further studies. GMS, Precirol ATO 5 and Compritol 888 were the lipids selected to determine solubility of drugs in various ratios i.e.1:1, 1:3 and 3:1. $10 \mathrm{mg}$ drug was taken individually and $100 \mathrm{mg}$ lipid was incrementally added in different ratios to solubilize the drug. The mixture of lipids and drugs was melted to above $5{ }^{\circ} \mathrm{C}$ of the respective melting points of the lipids and kept for stirring up to $24 \mathrm{~h}$. The amount of lipid required to solubilize ATS and VIN was determined by UV Vis Spectrophotometry at 246 and $273 \mathrm{~nm}$ [8]. The experiment was performed in triplicate. 


\section{Optimization of probe sonication time}

Preliminary trial batches of SLNs comprising of both ATS $(80 \mathrm{mg})$ and VIN $(20 \mathrm{mg})$ together (4:1 ratio) were prepared by hot emulsification-ultrasonication technique. The prepared emulsion was kept for probe sonication (Probe sonicator, PCI, Mumbai, India) at $40 \%$ amplitude with $20 \mathrm{kHz}$ frequency and after specific time intervals, i.e. $10,15,20,25$ and $30 \mathrm{~min} .1 \mathrm{ml}$ sample was withdrawn, appropriately diluted with double distilled water and particle size was analyzed by using Particle size analyzer (Horiba Scientific SZ 100, Japan).

\section{Central composite factorial design}

Optimization is an approach for product development to set the goal for prior knowledge of experiments from designing level to stability of product and assessment of the possible risks while carrying out the experiment. The goal is to develop the SLNs of lesser particle size with maximize EE and DL. Smaller particle size enhances the permeability and dissolution. Maximum EE and DL increases the therapeutic efficiency by improving bioavailability of drugs. These parameters influence the quality of the product as well as effectiveness of drug delivery by improving its therapeutic efficiency.

The optimization of SLNs was carried out by using Design Expert Software (Version 12, State ease. Inc, Minneapolis, USA). The Central Composite factorial design was used for optimization of SLNs and the polynomial equation was derived. CPP and CQA parameters considered for optimization are shown in Table 1. From the polynomial equation, we obtain information about the effects of CPP on CQA-either positive or negative. The best fitted model and equation is suggested on basis of statistical data i.e. multiple correlation coefficient (R2), adjusted multiple correlation coefficient (adjusted R2). The value of $P<0.05$ is considered as significant.

\section{Preparation of SLNs}

Hot emulsification-ultrasonication technique was used for preparation of SLNs. ATS (80 mg) and VIN (20 mg) were weighed accurately and added to the weighed quantity of GMS, Precirol ATO 5, and Tween 80. This mixture was melted at $5-10{ }^{\circ} \mathrm{C}$ above its melting point of respective solid lipids. Poloxamer 188 and Labrasol were dissolved in aqueous phase heated at $5{ }^{\circ} \mathrm{C}$ above its melting point in a separate beaker. When a clear lipid phase was attained, the aqueous phase was added drop wise into the hot lipidic phase at the same temperature and a primary hot emulsion was formed. This emulsion was homogenized by using high speed homogenizer (Eltek, India) for $10 \mathrm{~min}$ at varied speeds (3000-9000 rpm during optimization). After that the emulsion was ultrasonified by using a probe sonicator for $25 \mathrm{~min}$ at $40 \%$ amplitude with $20 \mathrm{kHz}$ frequency. The prepared emulsion was cooled in ice bath to form SLNs. The prepared SLNs were stored in a refrigerator and used for further analysis $[16,17]$.

\section{Characterization of SLNs \\ Particle size (PS) analysis, polydispersity index (PDI) and zeta potential (ZP)}

Particle size, PDI and zeta potential of the prepared formulations were evaluated using a Horiba Particle size analyzer and zeta sizer. Before analysis of the formulation, suitable dilution of the SLNs formulation (i.e. 10 times) was made by using double distilled water. The diluted sample was evaluated at a fixed scattered angle of $173{ }^{\circ} \mathrm{C}$ and $25{ }^{\circ} \mathrm{C}$ temperature. All the experimentation was performed in triplicate.

\section{Entrapment efficiency (EE) and drug loading (DL)}

\% EE of SLNs formulation was determined by centrifugation method. $2 \mathrm{ml}$ of the SLN formulations was taken in an eppendroff tube and sample was centrifuged at 10,000 RPM for $45 \mathrm{~min}$ in refrigerated centrifuge (Eltek

Table 1 Variables and their levels

\begin{tabular}{lllll}
\hline Types of variables & Levels & & & \\
\cline { 4 - 5 } & Low (-1) & Medium (0) & High (+1) & - Alpha \\
\hline Independent variables (CPP) & $1: 6.5$ & $1: 9$ & $1: 11.5$ & 4.79 \\
A. Drug: lipid ratio (mg) & $1: 0$ & $1: 1$ & $1: 2$ & -0.68 \\
B. Surfactant: co-surfactant ratio (mg) & 5000 & 7000 & 9000 & 3636.41 \\
C. Homogenization speed (rpm) & & & & 13.20 \\
Dependent variables (CQA) & & & & $10,363.6$ \\
Y1. Particle size (nm) & & & & \\
Y2. Entrapment efficiency (\%) & & & \\
Y3. Drug loading (\%) & & &
\end{tabular}

CPP, critical process parameters; CQA, critical quality attributes; $\mathrm{mg}$, milligram; $\mathrm{nm}$, nanometer; rpm, rotation per minute; \%, percent 
refrigerated centrifuge, Mumbai). The supernatant layer was collected and suitable dilutions were made using methanol. Unencapsulated drug content was analyzed by using UV Vis Spectrophotometer at 246 and $273 \mathrm{~nm}$. All the experimentation was performed in triplicate.

EE and drug loading was analyzed by using following equations analyzed using UV-Vis Spectrophotometer at 246 and $273 \mathrm{~nm}$. All the experiments were performed in triplicate.

\section{In vitro cell line study}

Human hepatoma HepG2, human breast cancer MCF 7 and murine skin melanoma B16 F10 cell lines were grown in RPMI 1640 medium containing 10\% fetal bovine

$$
\% \mathrm{EE}=\frac{\text { Amount of drug added in formulation }- \text { Amount of unencapsulated rug }}{\text { Amount of drug added in the formulation }} \times 100
$$

\% Drug loading was determined by entrapped drug and considered added quantity of solid lipid. The following formula is used to calculate \% drug loading serum and $2 \mathrm{mM}$ L-glutamine. For the present screening experiments, cells were inoculated into 96 well micro titer plates in $100 \mu \mathrm{L}$ at plating densities as shown in the

$$
\% \mathrm{DL}=\frac{\text { Amount of entrapped drug in SLNs formulation }}{\text { Amount of solid lipid added }+ \text { Amount of ATS and VIN added }} \times 100 \text {. }
$$

\section{Statistical analysis}

The effect of CPP on the CQA was estimated using statistical tools such as descriptive statistics and one way ANOVA with Stat Ease Design expert software V 12 (Minneapolis, MN). A value of $p<0.05$ was considered to be statistically significant.

\section{Transmission electron microscopy (TEM)}

TEM was carried out using JEM 2100F High resolution transmission electron microscope (HR-TEM $200 \mathrm{kV}$ ). SLNs was dispersed in water and a drop of that dispersion was loaded on 200- mesh carbon coated copper grid which had $3 \mathrm{~mm}$ diameter. The photomicrographs were taken and morphology was observed at 50X -1.5 MXand $200 \mathrm{kV}$ voltage.

\section{X-ray diffraction (X-RD) study}

X-RD study of ATS, VIN, blank SLNs, SLNs were carried out using X-ray diffractometer. Obtained results were analyzed and plotted by using Match 3 diffractometer software.

\section{In vitro drug release in PBS $\mathrm{pH} 7.4$}

In vitro release of optimized batch i.e. F3, ATS, VIN, ATS SLNs, and VIN SLNs were carried out in the PBS pH 7.4. $2 \mathrm{ml}$ of SLNs which were equivalent to $8 \mathrm{mg}$ and $2 \mathrm{mg}$ of ATS and VIN, respectively was filled in the pre-soaked dialysis bag and immersed in $200 \mathrm{ml}$ of PBS $\mathrm{pH} 7.4$ for $24 \mathrm{~h}$ in a beaker, stirred at $100 \mathrm{RPM}$ at a temperature of $37 \pm 0.5{ }^{\circ} \mathrm{C}$. $2 \mathrm{ml}$ aliquot was withdrawn after specified time intervals $0.5,1,2,3,4,5,6,7,8,12$ and $24 \mathrm{~h}$ and replenished with same amount of media to maintain sink conditions. The aliquot was filtered, suitably diluted and study details above, depending on the doubling time of individual cell lines. After cell inoculation, the micro titer plates were incubated at $37{ }^{\circ} \mathrm{C}, 5 \% \mathrm{CO} 2,95 \%$ air and $100 \%$ relative humidity for $24 \mathrm{~h}$ prior to the addition of the experimental drugs.

Experimental drugs were initially solubilized in water at $100 \mathrm{mg} / \mathrm{ml}$ and diluted to $1 \mathrm{mg} / \mathrm{ml}$ using DMSO and stored frozen prior to use. At the time of drug addition, an aliquot of frozen concentrate $(1 \mathrm{mg} / \mathrm{ml})$ was thawed and diluted to $100 \mu \mathrm{g} / \mathrm{ml}, 200 \mu \mathrm{g} / \mathrm{ml}, 400 \mu \mathrm{g} / \mathrm{ml}$ and $500 \mu \mathrm{g} / \mathrm{ml}$ for HepG2; $100 \mu \mathrm{g} / \mathrm{ml}, 200 \mu \mathrm{g} / \mathrm{ml}, 400 \mu \mathrm{g} / \mathrm{ml}$ and $800 \mu \mathrm{g} / \mathrm{ml}$ for MCF 7 and melanoma B16F10 with complete medium containing the test article. Aliquots of $10 \mu \mathrm{l}$ of these different drug dilutions were added to the appropriate micro titer wells already containing $90 \mu \mathrm{l}$ of medium, resulting in the required final drug concentrations i.e. $10 \mu \mathrm{g} / \mathrm{ml}, 20 \mu \mathrm{g} / \mathrm{ml}, 40 \mu \mathrm{g} / \mathrm{ml}, 50 \mu \mathrm{g} / \mathrm{ml}$ for HepG2 and $10 \mu \mathrm{g} / \mathrm{ml}, 20 \mu \mathrm{g} / \mathrm{ml}, 40 \mu \mathrm{g} / \mathrm{ml}, 80 \mu \mathrm{g} / \mathrm{ml}$ for MCF 7 and melanoma B16F10.

After compound addition, plates were incubated at standard conditions for $48 \mathrm{~h}$ and assay was terminated by the addition of cold TCA. Cells were fixed in situ by the gentle addition of $50 \mu \mathrm{l}$ of cold $30 \%$ (w/v) TCA (final concentration, $10 \% \mathrm{TCA}$ ) and incubated for $60 \mathrm{~min}$ at $4{ }^{\circ} \mathrm{C}$. The supernatant was discarded; the plates were washed five times with tap water and air dried. Sulforhodamine B (SRB) solution $(50 \mu \mathrm{l})$ at $0.4 \%(\mathrm{w} / \mathrm{v})$ in $1 \%$ acetic acid was added to each of the wells, and plates were incubated for $20 \mathrm{~min}$ at room temperature. After staining, unbound dye was recovered and the residual dye was removed by washing five times with $1 \%$ acetic acid. The plates were air dried. Bound stain was subsequently eluted with $10 \mathrm{mM}$ trizma base, and the absorbance was read on a 
plate reader at a wavelength of $540 \mathrm{~nm}$ with $690 \mathrm{~nm}$ reference wavelength.

Percent growth was calculated on a plate-by-plate basis for test wells relative to control wells. Percent Growth was expressed as the ratio of average absorbance of the test well to the average absorbance of the control wells * 100.

Using the six absorbance measurements [time zero $(\mathrm{Tz})$, control growth $(\mathrm{C})$, and test growth in the presence of drug at the four concentration levels (Ti)], the percentage growth was calculated at each of the drug concentration levels. Percentage growth inhibition was calculated as $[18,19]$ :

$$
[\mathrm{Ti} / \mathrm{C}] \times 100 \%
$$

Data were represented as mean \pm SD. The IC50 values were calculated by using Graph pad prism V5.0 (Graph Pad Software Inc., San Diego, CA, USA) utilizing nonlinear regression analysis. The statistical significance was determined using two-way ANOVA and $P<0.05$ was considered to be statistically significant.

\section{In vitro cytotoxicity and synergistic effects}

The synergistic effect between SLNs, Free ATS and Free VIN on HEPG 2 cells was determined on the basis of better results compared to the other cell lines. HEPG 2 cells were treated with the combinations at the dose ratio of $4: 1$, based on the concentration of loaded drugs in SLNs. Combination Index (CI) analysis of free drug combination which is based on the Chou and Talalay method was found out using CompuSyn Software Version 1 (ComboSyn, Inc, UK). Briefly, for each level of $\mathrm{Fa}$ (the fraction of affected cells), the CI values of SLNs was produced. The $\mathrm{CI}$ values curves were drawn according to $\mathrm{Fa}$. The Fa value $(0.2$ to 0.8$)$ is considered as validated. $\mathrm{CI}<1$ represents synergism and $\mathrm{CI}>1$ represents antagonism, respectively [20].

\section{Stability studies}

SLNs formulation (F3) was kept at $4 \pm 1{ }^{\circ} \mathrm{C}$ in a refrigerator and at room temperature $\left(25 \pm 1{ }^{\circ} \mathrm{C}\right)$ for 6 months. The formulation was analyzed after specific intervals 1,2 , 3 and 6 months for Particle size, PDI and \% EE [21]. All the experiments were performed in triplicate.

\section{Results}

\section{Screening of solid lipids}

The excipients used in the SLNs system having high solvable capacity for drug ensuring solubilization of drug in the resultant emulsion. The results of solubility studies of ATS and VIN in various solid lipids are shown in Table 2. ATS and VIN showed maximum solubility in the GMS, Precirol ATO 5, Compritol 888 ATO and Gelucire. ATS and VIN exhibited highest solubility in GMS as well as in the Precirol ATO5. Thus, these solid lipids were selected for further combinational lipid solubility studies.

\section{Screening of surfactant and co-surfactant}

ATS showed higher solubility in Tween 80 and Span 80 which act as the main surfactants, whereas VIN also showed maximum solubility in Triton X 100, Tween 20, Span 20 and Span 80. Tween 80 showed more than $10 \mathrm{mg} / 2 \mathrm{ml}$ solubility in both drugs. Tween 80 was selected as a common surfactant for both drugs on the basis of solubility and stability of the dispersion system. ATS and VIN both showed maximum solubility in Labrasol which is used as secondary surfactant or cosurfactant and it helps to reduce the particle size. Thus, labrasol and Tween 80 were selected for the preparation of SLNs. Poloxamer 188 was selected as surfactant which also acts as stabilizer along with Tween 80 . The results of solubility studies of ATS and VIN in various surfactants and co- surfactants are shown in Table 2. Surfactant and co-surfactant were used individually and in combination ratios i.e. 1:0, 1:1 and 1:2. These ratios were selected to check the influence of surfactant and co-surfactant on particle size and stability of the SLNs.

\section{Screening of solid lipids ratio}

The solubility of both drugs in Compritol 888: Precirol ATO5 was found to be very less in the range of 0.46$0.85 \mathrm{mg} / \mathrm{gm}$ and $0.83-1.15 \mathrm{mg} / \mathrm{gm}$ for ATS and VIN, respectively in all the ratios 1:1, 1:3 and 3:1 as compared to GMS: Precirol ATO5; whereas 9.84-25.54 mg/gm and $5.52-16.02 \mathrm{mg} / \mathrm{gm}$ in GMS: Precirol ATO5 for ATS and VIN. In GMS both drugs are highly soluble but when the concentration of Precirol ATO5 increases solubility of both drugs decreased. Thus we have selected 1:1 ratio of GMS: Precirol ATO 5 for design and development of the formulation.

HLB value of GMS: Precirol ATO5 are 3.8 and 2, respectively as compared to Compritol 888: Precirol ATO5 (1 and 2). ATS and VIN showed more solubility in GMS: Precirol ATO5 due to its higher HLB value which itself indicates higher lipophilicity. Thus, it helps to solubilize both drugs. The solubility results are shown in Table 2.

\section{Optimization of probe sonication time}

The coarse emulsion was broken down into nano emulsion by using probe sonication technique. As the sonication time increases, particle size decreases. It means that sonication time is directly proportional to the particle size (Table 3). The effect of sonication time was positive till $25 \mathrm{~min}$ after that it showed a negative effect. It revealed that $25 \mathrm{~min}$ was the optimized time 
Table 2 Solubility studies of ATS and VIN in solid lipids, surfactant, co-surfactant and combination of solid lipids

\begin{tabular}{|c|c|c|}
\hline Solid lipids & ATS solubility (mg/gm) & $\begin{array}{l}\text { VIN solubility } \\
\text { (mg/gm) }\end{array}$ \\
\hline Cetyl palmitate & 5.99 & 0.60 \\
\hline Stearic acid & 2.53 & 1.78 \\
\hline Emulcire & 10.27 & 1.07 \\
\hline Gelucire & 23.57 & 2.28 \\
\hline Compritol 888 & 26.12 & 2.42 \\
\hline Precirol ATO 5 & 27.83 & 3.67 \\
\hline GMS & 34.16 & 6.52 \\
\hline \multicolumn{3}{|c|}{ Surfactant, co-surfactant (mg/2 ml) } \\
\hline Tween 20 & 6.40 & 55.30 \\
\hline Tween 80 & 10.4 & 19.53 \\
\hline Span 20 & 9.00 & 19.38 \\
\hline Span 80 & 12.37 & 11.37 \\
\hline Triton $\times 100$ & 9.06 & 40.96 \\
\hline Labrasol & 65.14 & 69.2 \\
\hline Poloxamer 188 & 7.01 & 1.681 \\
\hline Poloxamer 407 & 5.26 & 7.11 \\
\hline Ratio & Compritol 888 + Precirol ATO 5 & $\begin{array}{l}\text { GMS + Precirol } \\
\text { ATO } 5\end{array}$ \\
\hline \multicolumn{3}{|c|}{ ATS solubility (mg/gm) } \\
\hline 1:01 & 0.46 & 15.85 \\
\hline 1:03 & 0.85 & 9.84 \\
\hline 3:01 & 0.60 & 25.54 \\
\hline \multicolumn{3}{|c|}{ VIN solubility (mg/gm) } \\
\hline $1: 01$ & 0.93 & 10.56 \\
\hline 1:03 & 1.15 & 5.52 \\
\hline 3:01 & 0.83 & 16.02 \\
\hline
\end{tabular}

Gm, gram; ml, milliliter

Table 3 Optimization of probe sonication time

\begin{tabular}{lc}
\hline Probe sonication time (mins) & $\begin{array}{l}\text { Particle } \\
\text { size }(\mathbf{n m})\end{array}$ \\
\hline 10 & 1538 \\
15 & 1281 \\
20 & 894 \\
25 & 320 \\
30 & 736 \\
\hline
\end{tabular}

Mins, minutes

of sonication i.e. threshold time after that, outer core of lipid disrupts and resulting drug molecule leaches out into the external phase and hence aggregation of particle take place and larger particle size was observed. It may be due to the insufficiency of surfactant that a larger particle size formed. Higher concentration of surfactant helps to reduce the particle size and the formulation becomes more stable $[8,22]$. Longer exposure to sonication causes agglomeration of particles size after the initial size reduction [23].

\section{Central composite factorial design}

Central composite factorial design was implemented to analyze the positive effect, adversary effect and experimental model effect on CPP and CQA. Fifteen batches were prepared and results of all formulated batches are shown in Table 4. The model analysis and model fitted statistical values are depicted in Table 5 .

The effect of CPP factors on CQA are represented graphically by using response surface plots. These response surface plots are shown in Fig. 1 and influence of CPP are given in the discussion.

The ratio of drug lipid influences (A) the particle size and shows positive effect on Particle size, \% EE because lipids are needed to encapsulate the drugs but it shows negative effect on \% DL due to the amount of lipids as well as encapsulation. Thus, parameter A significantly influences particle size. Surfactant: Co-surfactant (B) 
Table 4 Optimized coded batches and results of coded batches

\begin{tabular}{|c|c|c|c|c|c|c|c|c|c|}
\hline $\begin{array}{l}\text { Coded } \\
\text { batches }\end{array}$ & $\begin{array}{l}\text { A } \\
\text { D:L (mg) }\end{array}$ & $\begin{array}{l}\text { B } \\
\text { Surfactant: } \\
\text { co-surfactant } \\
\text { (mg) }\end{array}$ & $\begin{array}{l}\text { C } \\
\text { Homogenization } \\
\text { speed (RPM) }\end{array}$ & $\begin{array}{l}\text { Y1 } \\
\text { Particle } \\
\text { size (nm) }\end{array}$ & $\begin{array}{l}\text { Y2 } \\
\% \text { EE (ATS) }\end{array}$ & $\begin{array}{l}\text { Y3\% } \\
\text { EE (VIN) }\end{array}$ & $\begin{array}{l}\text { Y4 } \\
\% \text { DL }\end{array}$ & PDI & ZP (-emv) \\
\hline $\mathrm{F} 1$ & 100: (450:450) & $500: 500$ & 7000 & $398 \pm 4.2$ & $55 \pm 2.21$ & $57.5 \pm 1.54$ & $5.55 \pm 0.35$ & $0.593 \pm 0.0 .8$ & $32.7 \pm 0.65$ \\
\hline F2 & 100: (575:575) & 333:667 & 9000 & $446 \pm 2.8$ & $60 \pm 0.83$ & $62.05 \pm 2.24$ & $4.75 \pm 0.8$ & $0.417 \pm 0.06$ & $-29.2 \pm .0 .91$ \\
\hline F3 & 100: (450:450) & $120: 880$ & 7000 & $323 \pm 6.0$ & $64.69 \pm 1.1$ & $65.98 \pm 0.91$ & $6.49 \pm 0.76$ & $0.333 \pm 0.02$ & $-30.4 \pm 0.66$ \\
\hline F4 & 100: (450:450) & 1000:0 & 7000 & $479 \pm 2.5$ & $44.93 \pm 1.56$ & $50.67 \pm 1.84$ & $4.6 \pm 0.58$ & $0.648 \pm 0.10$ & $-32.6 \pm 0.15$ \\
\hline F5 & 100: (325:325) & 1000:0 & 9000 & $457 \pm 7.1$ & $45.4 \pm 2.73$ & $38.3 \pm 3.9$ & $6.02 \pm 0.45$ & $0.69 \pm 0.12$ & $-38.2 \pm 0.19$ \\
\hline F6 & 100: (660:660) & 500:500 & 7000 & $591 \pm 5.3$ & $52.74 \pm 3.26$ & $50.3 \pm 2.81$ & $4.11 \pm 0.86$ & $0.454 \pm 0.06$ & $-56.2 \pm 1.5$ \\
\hline F7 & 100: (325:325) & 1000:0 & 5000 & $429 \pm 3.0$ & $55.67 \pm 2.32$ & $57.76 \pm 1.96$ & $7.62 \pm 0.91$ & $0.403 \pm 0.05$ & $-35.3 \pm 0.7$ \\
\hline F8 & 100: (480:480) & 500:500 & 7000 & $409 \pm 4.3$ & $56 \pm 0.94$ & $53.9 \pm 1.35$ & $7.61 \pm 0.23$ & $0.612 \pm 0.09$ & $-25.2 \pm 0.98$ \\
\hline F9 & 100: (575:575) & 1000:0 & 5000 & $615 \pm 5.6$ & $58.46 \pm 1.32$ & $53.6 \pm 2.45$ & $4.52 \pm 0.11$ & $0.62 \pm 0.07$ & $-34.3 \pm 0.58$ \\
\hline F10 & 100: (325:325) & 333:667 & 9000 & $426 \pm 8.4$ & $54.74 \pm 1.58$ & $49.83 \pm 2.17$ & $7.36 \pm 0.14$ & $0.574 \pm 0.08$ & $-.35 .1 \pm 1.5$ \\
\hline F11 & 100: (325:325) & 333:667 & 5000 & $436 \pm 1.9$ & $56.73 \pm 0.74$ & $42.8 \pm 0.35$ & $7.3 \pm 0.097$ & $0.334 \pm 0.05$ & $17.9 \pm 1.4$ \\
\hline $\mathrm{F} 12$ & 100: (450:450) & $500: 500$ & 3636.41 & $532 \pm 9.5$ & $47.7 \pm 1.44$ & $42.65 \pm 0.79$ & $4.67 \pm 0.1$ & $0.867 \pm 0.15$ & $-30.7 \pm 2.23$ \\
\hline F13 & 100: (450:450) & $500: 500$ & $10,363.6$ & $518 \pm 5.6$ & $47 \pm 0.89$ & $40.6 \pm 2.1$ & $4.57 \pm 0.192$ & $0.513 \pm 0.06$ & $-32.7 \pm 1.85$ \\
\hline $\mathrm{F} 14$ & 100: (575:575) & 1000:0 & 9000 & $537 \pm 4.5$ & $52.73 \pm 2.32$ & $41.45 \pm 3.04$ & $3.97 \pm 0.108$ & $0.735 \pm 0.11$ & $-36.9 \pm 1.52$ \\
\hline F15 & 100: (575:575) & $333: 667$ & 5000 & $465 \pm 4.0$ & $58.62 \pm 1.84$ & $54.07 \pm 1.12$ & $4.53 \pm 0.16$ & $0.396 \pm 0.04$ & $-34.4 \pm 1.62$ \\
\hline
\end{tabular}

Optimized coded batches: F1-F15, amount of poloxamer (used as a stabilizer)-200 mg, ratio of lipid- mixture used (GMS: Precirol ATO 5) -1:1, total amount of surfactant and co-surfactant mixture (Tween 80 and Labrasol) $-1000 \mathrm{mg}$

Table 5 Model analysis and model fitted statistical values

\begin{tabular}{|c|c|c|c|c|c|}
\hline CQA parameters & Model suggested & $\begin{array}{l}\text { Model } \\
\text { significance } \\
\text { value }\end{array}$ & Lack of fit value & $R^{2}$ value & Model's mathematical equation \\
\hline Particle Size & Quadratic model & $<0.0001$ & 2628.2 & 0.974 & $\begin{array}{l}398.12+45.48 * A-38.62 * B-7.51 * C-27.13 * A B-14.38 * A C+ \\
2.62 * B C+35.29 A^{2}+2.90 * B^{*}+44.13^{*} C^{2}\end{array}$ \\
\hline$\%$ EE (ATS) & Cubic model & 0.0214 & 34.53 & 0.924 & $\begin{array}{l}54.89+0.9656^{*} A+3.84 * B-1.20 * C-0.1963 * A B+2.10 * B C+0 \\
.5081 * A^{2}+0.663^{*} B^{2}-1.97 * C^{2}\end{array}$ \\
\hline$\% \mathrm{EE}(\mathrm{VIN})$ & Cubic model & $<0.0001$ & 0.0390 & 0.999 & $\begin{array}{l}57.5+1.33 * A+3.18 * B-1.47 * C+3.06 * A B+1.03 * A C+5.83 * B \\
C-2.1{ }^{*}{ }^{*} A^{2}+0.2684^{*} B^{2}-5.64 * C^{*}\end{array}$ \\
\hline$\% \mathrm{DL}$ & Quadratic model & $<0.0001$ & 1.24 & 0.951 & $\begin{array}{l}5.54-1.20 * A+0.365^{*} B-0.149 * C 0.0288^{*} A B+0.1512^{*} A C+0.3 \\
037 * B C+0.2003 A^{2}+0.0889 * B^{2}-0.238 * C^{2}\end{array}$ \\
\hline
\end{tabular}

$E E$, entrapment efficiency; DL, drug loading; A, drug lipid ratio; B, surfactant co surfactant ratio; $C$, homogenization speed

influences positively on all aspects except Particle size due to a lesser concentration which is insufficient to stabilize the SLNs. As the surfactant, co-surfactants are essential for solubilization of drugs which directly influences the EE and DL. Homogenization speed (C) affects negatively on all parameters because it's directly related to all the CQA parameters.

\section{Particle size, PDI and zeta potential}

The PS, PDI and ZP results of all the batches are shown in Table 4. The optimized batch F3 showed $323 \pm 6.0$ PS which is lesser than other batches. PDI values showed homogeneity of optimized formulation and negative values of ZP were found which self indicates that all the formulations are stable with uniform PS.

\section{\% Entrapment efficiency and \% drug loading}

$\%$ EE, \% DL results of all the batches are shown in Table 4. Maximum \% EE for both drugs i.e. ATS and VIN, respectively $(64.69 \pm 1.1,65.98 \pm 0.913)$ were found as well as \% DL was 6.49. The observed values and predicated values of CQA are shown in Table 6.

\section{Transmission electron microscopy}

TEM photomicrographs of optimized SLNs are shown in Fig. 2. Morphologically the SLNs formulation was observed 

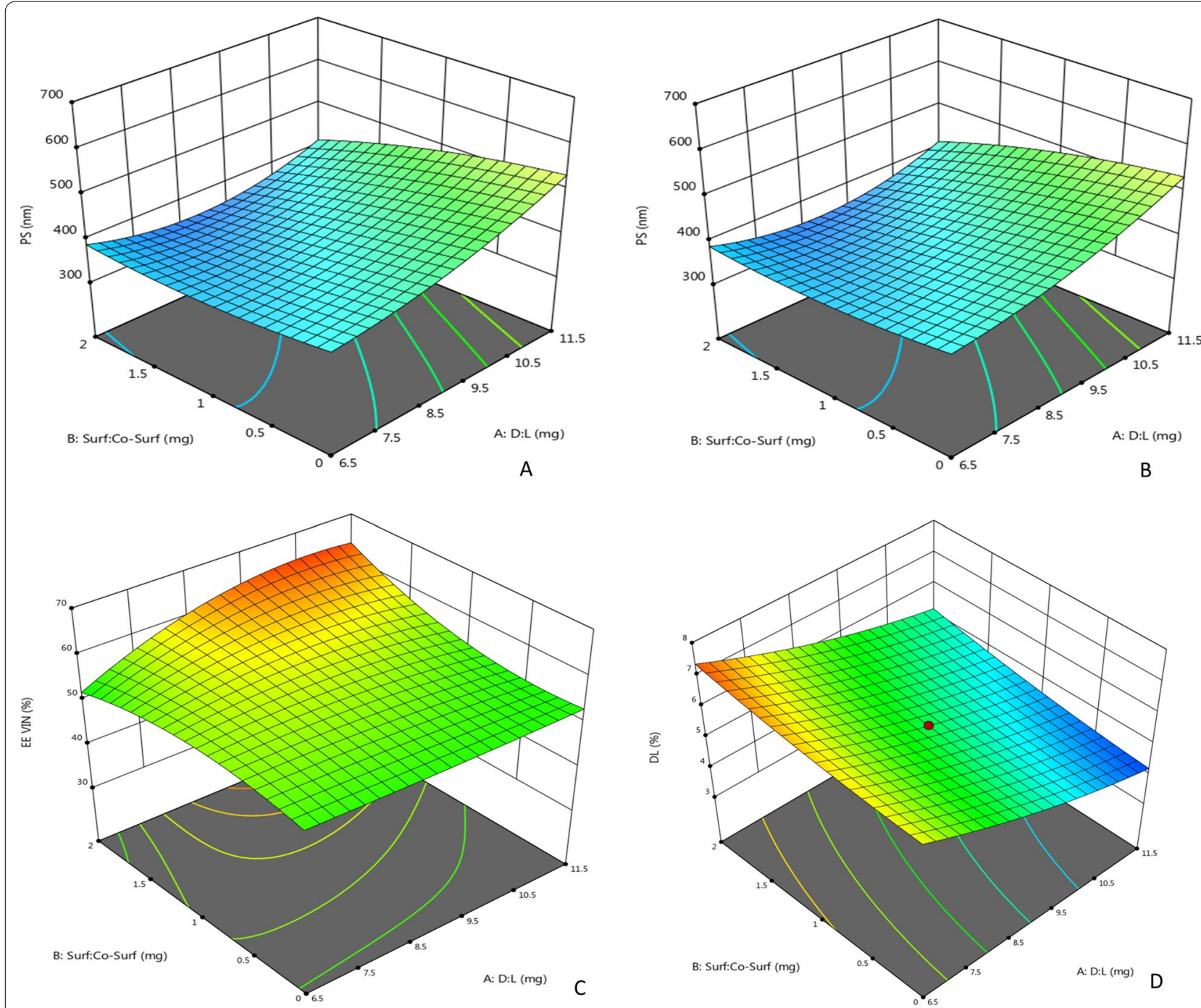

Fig. 1 Response surface plot of a particle size, b EE (ATS), c EE (VIN), d DL

to be spherical in shape and particle size of formulation was also confirmed by TEM study. Nanoparticles were observed of less than $100 \mathrm{~nm}$ size, which are spherical in shape.

\section{$X$-ray diffraction study}

The sharp peaks of ATS, VIN due to crystalline nature were not observed in the SLNs loaded with both the drugs. The diffraction patterns of drugs loaded SLNs and Blank SLNs showed there was no significant change in their peak patterns, indicating that addition of both drugs did not change the nature SLNs. SLNs formulation revealed that there was less intensity of peaks observed when compared to individual peaks of both drugs i.e. ATS and VIN. It means that the crystalline nature of both drugs was not observed in the drug loaded SLNs formulation and drugs were appropriately encapsulated in
Table 6 Observed versus Predicted values of optimized batch F3

\begin{tabular}{lcl}
\hline Response & Predicted values & Observed values \\
\hline PS $(\mathrm{nm})$ & 320.94 & 323 \\
$\%$ EE ATS & 66.54 & 64.69 \\
$\%$ EE VIN & 65.91 & 65.98 \\
$\%$ DL & 6.55 & 6.49 \\
\hline
\end{tabular}

DL- drug loading

the lipid core. The analyzed X-RD patterns are shown in Fig. 3.

\section{In vitro release studies in PBS 7.4}

Free ATS drug showed $69.26 \%$ release which was very close to ATS SLNs i.e. 67.64\%. The optimized SLNs 


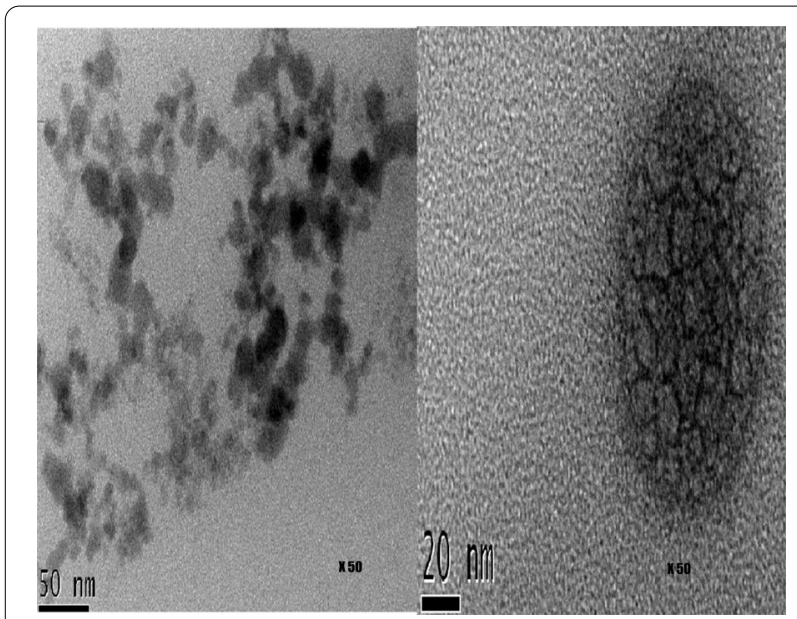

Fig. 2 TEM photomicrographs of optimized SLNs (F3)

formulation F3 showed $89.45 \%$ release up to $24 \mathrm{~h}$. Simultaneously, VIN also showed $45.55 \%, 47.04 \%$ and $91.86 \%$ release up to $24 \mathrm{~h}$ of free VIN, VIN SLNs and F3 formulation, respectively. The release pattern of both drugs is shown in Figs. 4 and 5.

\section{In vitro cell line study}

SRB assay was performed on the HepG2, MCF 7 and melanoma B16 F10 cell line. Plain ATS, Plain VIN, blank SLNs and SLNs were used to evaluate anti-tumor activity of SLNs formulation. IC 50 values are mentioned in Table 7. The growth curve of human hepatic cell line HepG2, MCF 7 and melanoma B16 F10 are shown in Figs. 6, 7 and 8. However, when both drugs were incorporated in to the SLNs drug delivery, required concentrations for its tumor activity was reduced. The effective concentration of SLNs was less i.e. 1.04, 12.97 and $8.06 \mu \mathrm{g} / \mathrm{ml}$ for HepG2, MCF 7 and melanoma B16 F10, respectively compared to the individual SLNs or free drugs alone.

\section{In vitro cytotoxicity and synergistic effects}

$\mathrm{CI}$ value of SLNs is less than 1 as shown in the $\mathrm{Fa}-\mathrm{CI}$ plot (Fig. 9a). To get desirable higher synergistic effect, a higher concentration is required which may directly lower the CI value. $0.8 \mathrm{CI}$ value was found with $0.5 \mathrm{Fa}$ which signifies synergistic effect. DRI (Dose reduction index) value is more than 1and is self-indicative that dose reduction is favorable in the SLNs. SLNs formulation at

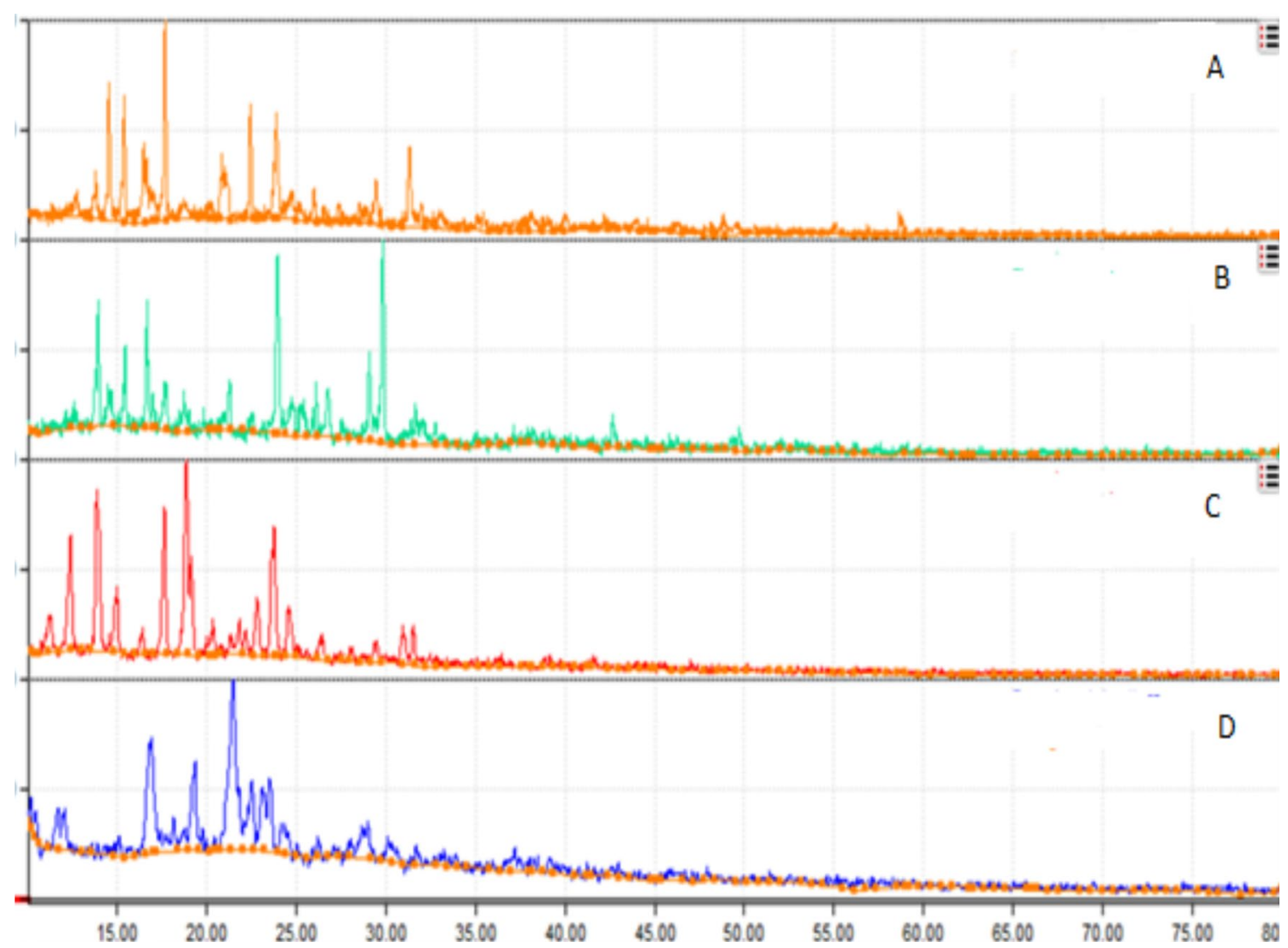

Fig. 3 X-RD patterns of a SLNs (F3), b Blank SLNs, c VIN, d ATS 

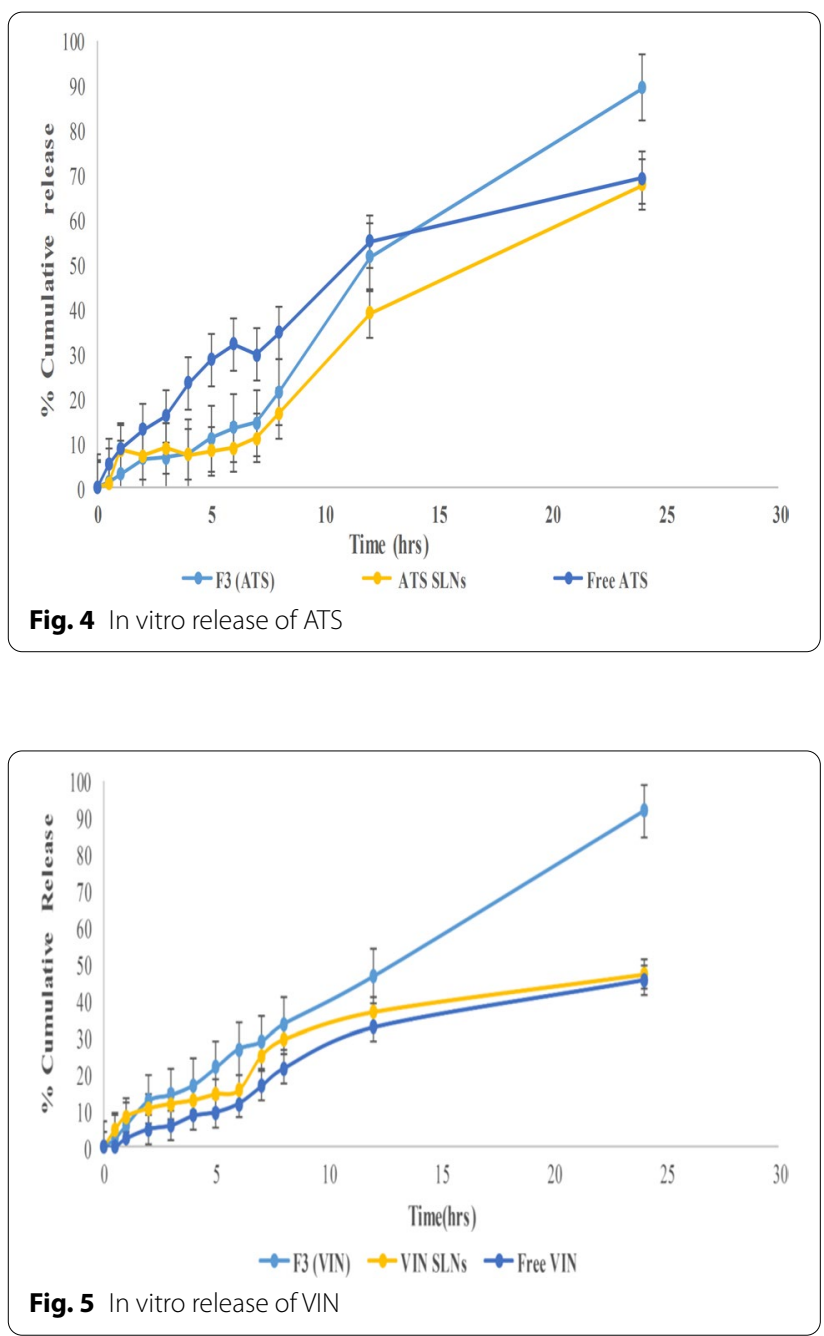

highest concentration i.e. $50 \mu \mathrm{g} / \mathrm{ml}$ formulation achieves the desired cytotoxic effect (Table 8; Fig. 9b).

\section{Stability studies}

SLNs formulation i.e. F3 was evaluated after specific intervals which was kept for stability studies at RT and $4{ }^{\circ} \mathrm{C}$ refrigerated conditions. There was no significant change in the Particle size and entrapment efficiency for both drugs. The formulation was stable at both temperatures up to 3 months after which the particle size increased for the RT sample. This happened due to the excipient which are present in the formulation i.e. Precirol ATO 5 (Precirol ATO 5 is kept in refrigerated condition). It means that the storage condition for SLNs is $4{ }^{\circ} \mathrm{C}$ and refrigeration is needed to keep the formulation stable. The results are shown in Table 9 and student $t$ test was applied for particle size, EE for both drugs at refrigerated conditions and RT. Experiments were performed in triplicate and results showed $p<0.05$ value which is insignificant.

\section{Discussion}

Several factors were considered and evaluated while designing, optimizing the formulations i.e. selection of solids lipids, surfactants, probe sonication time as well as CPP. The quadratic model was suggested for particle size and ANOVA was found to be significant which is depicted in Table 5 . Particle size is directly proportional to solid lipid content [24] and surfactant: co surfactant ratio is also directly proportional (Fig. 1a). As the solid lipid content decreases, emulsifying efficiency decreases and agglomeration of particles increases which results in increment in the particle size and broader the PDI. Tween 80 and labrasol together helps to reduce the particle size by improving emulsification and solubilization of drug.

The cubic model was suggested for EE of both drugs and ANOVA was found to be significant which is depicted in Table 5. Labrasol helps to reduce the particle size when it used in optimized concentration/ ratio with tween 80 i.e. 1:2. As the lipid content increases entrapment efficiency also increases due to availability of more space to encapsulate the drug molecules. It also reduces the leaking of drugs into the external phase i.e. aqueous phase, thus EE increases (Fig. 1b, c) [25, 26].

EE of SLNs increased with increasing co-surfactant concentration i.e. labrasol. Higher concentration of surfactant and co-surfactant leads to efficient drug loading and retention of molecules within the nanoparticle dispersion or on the surface of smaller nanoparticles [22]. Thus, the aggregation is prevented. It was observed that when tween 80 was used in 1:0 ratio, EE of ATS increased and EE of VIN decreased. When tween 80 was used with labrasol in 1:2 and 1:1 ratio, EE of both drugs increased.

The cubic model was suggested for DL and ANOVA was found to be significant which is depicted in Table 5 . DL was affected due to the amount of lipid and concentration of surfactant: co-surfactant. Higher amount of lipid affects the entrapment efficiency which lowers the drug loading capacity with the proportion of the lipid. Concentration of surfactant:co-surfactant increased the solubility of the drug and entrapment efficiency which influenced DL. Hence, DL also increased (Fig. 1d).

Homogenization speed influences the particle size and PDI. High kinetic energy produced at high RPM and poor drug loading in the SLNs matrix leads to change in lipid matrix structure, it gets ruptured and therefore the chances of leaching out of the drug moiety from lipid matrix into the external phase i.e. aqueous. Also, due to high kinetic energy aggregation and formation of larger nanoparticle takes place. 
Table 7 IC 50 values of Hepatoma Hep-G2, MCF-7 and melanoma B16 F10 cancer cell line

\begin{tabular}{lccc}
\hline Formulations & Hep-G2 $(\boldsymbol{\mu g} / \mathbf{m l})$ & MCF 7 $(\boldsymbol{\mu g} / \mathbf{m l})$ & $\begin{array}{l}\text { Melanoma } \\
(B 16 \text { F10) } \boldsymbol{\mu g} / \\
\mathbf{m l}\end{array}$ \\
\hline Free ATS & 17.71 & 26.62 & 29.22 \\
Free VIN & 10.51 & 273.1 & 252.0 \\
ATS SLNs & 17.12 & 41.91 & 4.17 \\
VIN SLNs & 2.85 & 59.31 & 12.51 \\
SLNs & 1.04 & 12.97 & 8.06 \\
\hline
\end{tabular}

$\mu \mathrm{g}$, microgram; MCF-7, Michigan cancer foundation-7; Hep G2-hepatoma G2

The ratio of Surfactant: Co-surfactant and Lipid ratio is also important for reduction in the particle size. Higher concentration of surfactant and co-surfactant reduces the surface tension of melted liquid droplets of lipids which helps to breakdown liquid droplets into smaller particle size [26]. Tween 80 is inadequate to solubilize the drug, reduce particle size and produce a homogenous dispersion [27]; thus an optimum concentration of labrasol and Tween 80 is required to reduce the particle size and solubilize the drugs.

Sufficient amount of surfactant and co surfactant was required to cover the smaller liquid droplets, which stabilized the formulation and prevented aggregation of nanoemulsion droplets [28]. The aggregation of nanoparticles takes place on storage when the concentration of surfactant and surfactant was insufficient and low. Thus, optimized amount of surfactant and co-surfactant is needed to make a stable nanoemulsion and also reduce the particle size [22].

Poloxamer 188 acts a steric stabilizer which helps to decrease the ZP due to change in particles shear plane. A high $Z P>30$ can provide negative and positive charge on the nanoparticle which shows the degree of repulsion between adjacent or equally charged particles in the dispersion. This repulsion force prevents aggregation of the nano particles and makes an electrically stable SLN dispersion [29-31]. Generally negative charge is preferred which helps to make stable dispersion by repulsion phenomenon between the charged particles owing to steric stabilizing effect of tween 80 [32]. The combination of surfactant and co surfactant helped to increase the $\mathrm{ZP}$ and hence all the batches showed $\mathrm{ZP}>-25$. ZP results showed that all the SLNs batches having good stability.

Both drugs are released simultaneously without affecting each other and showed sustained release effect. The drug showed sustained release up to $24 \mathrm{~h}$ due to encapsulation in the lipid core and increased the retention time in the intestine. The drug release increased as contact time between formulation and PBS 7.4 increased.

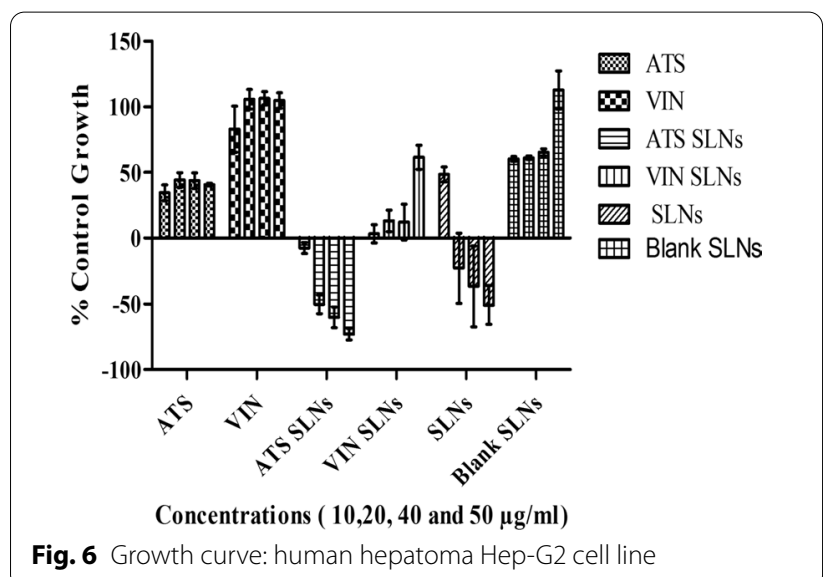

Fig. 6 Growth curve: human hepatoma Hep-G2 cell line

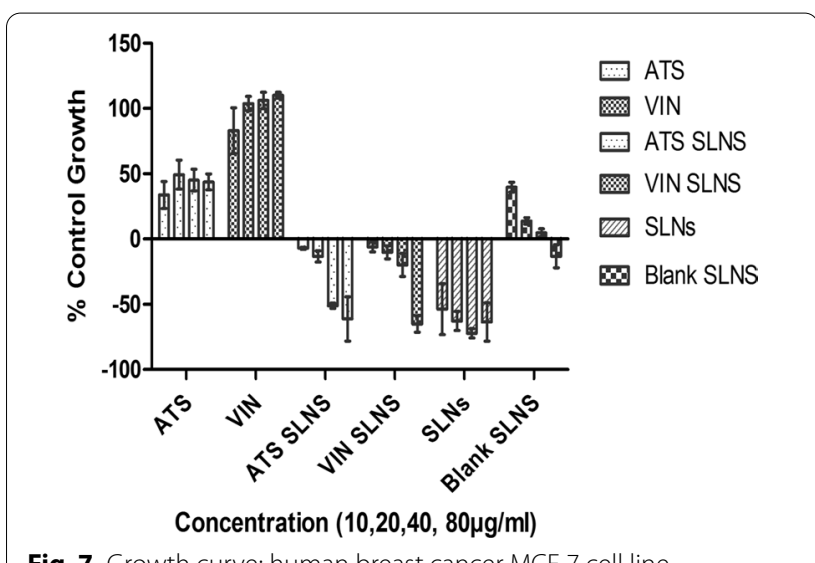

Fig. 7 Growth curve: human breast cancer MCF 7 cell line

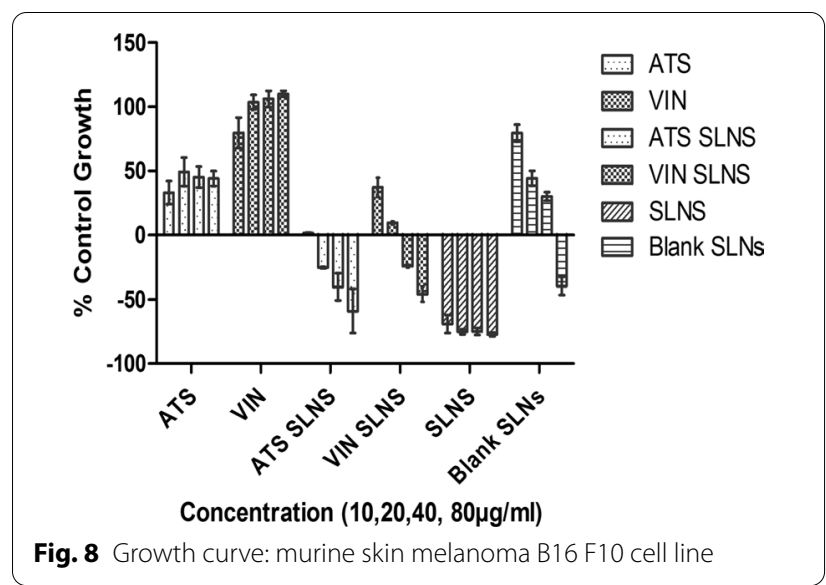

Free ATS and VIN showed less growth control rate as compared to SLNs. It shows that free drugs are unable to pass through the cell membrane and are unable to control the growth of HepG2, MCF 7 and melanoma B16 F10 cells efficiently. The free drugs when loaded in 

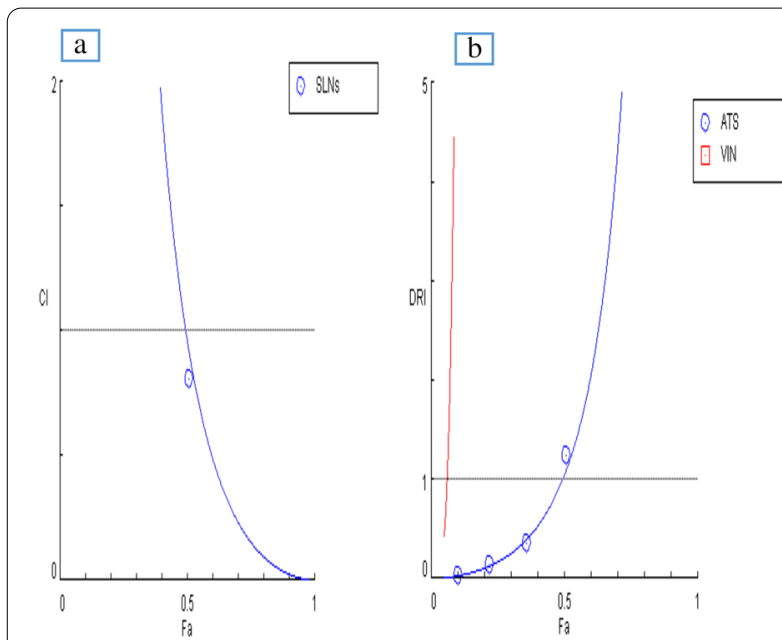

Fig. 9 Synergistic effect of SLNs a Fa-Cl values of SLNs, b DRI plot of SLNS

the SLNs formulation, showed a superior effect on the HepG2 cells as well as on MCF 7 and melanoma B16 F10 and efficiently controlled the growth. The SLNs exhibited stronger anti-cancer efficiency than individual ATS and VIN and dose dependent effect to control the growth of cancer cell and lethality [33]. The SLNs improve the cellular uptake and also enabled sustained drug release internally $[26,34,35]$. It shows that SLNs is an appropriate,

Table $8 \mathrm{Cl}$ values of SLNs

\begin{tabular}{llr}
\hline Total dose $(\boldsymbol{\mu g} / \mathbf{m l})$ & \multicolumn{2}{l}{ SLNs } \\
\cline { 2 - 3 } & Fa & \multicolumn{1}{c}{ Cl } \\
\hline 10.0 & 0.102 & 36.642 \\
20.0 & 0.22 & 7.854 \\
40.0 & 0.36 & 2.889 \\
50.0 & 0.509 & 0.806 \\
\hline
\end{tabular}

$\mathrm{Fa}$, fraction of affected cells; $\mathrm{Cl}$, combination index effective nano drug delivery and suitable for both drugs which may elicit their efficacy by attaining target of cancer cells.

From the results of in vitro cell line and ComuSyn results it is proved that the dose of individual free drug is insufficient to control the growth of HEPG2 cancer cell line. Both drugs when incorporated into the SLNs reduced the dose of individual drug and showed better results by reaching to the cancer cells. ATS and VIN showed synergistic effect when used together in higher concentration and this supports the results of in vitro cell line. The SLNs drug delivery system exhibited sustained release pattern, synergistic effect and is stable for prolonged time. Drugs are encapsulated in to a lipid core which may help to delivery drugs more efficiently to tumor cells and augment its therapeutic efficacy.

\section{Conclusions}

The SLNs drug delivery was developed and optimized successfully by using QbD approach. High speed homogenization followed by probe sonication method was used to prepare a SLNs formulation. The individual effects of CPP on CQA were evaluated using central composite design to get the stable and desired quality of SLNs formulation. Optimized batch of SLNs (F3) showed 64.69\% and $65.98 \%$ entrapment of ATS and VIN, respectively. Also F3 showed particle size of $323 \mathrm{~nm}$ with $0.333 \pm 0.02$ PDI and $-30.4 \pm 0.66 \mathrm{emv}$ ZP. The XRD pattern of SLNs formulation showed the both drugs are properly encapsulated in the lipid core. In vitro release of ATS and VIN were found to be $89.45 \%$ and $91.86 \%$, respectively at $24 \mathrm{~h}$ which indicated that SLNs showed sustained release effect. In vitro cell line study showed that SLNs formulation efficiently controlled the growth of HepG2, MCF 7 and melanoma B16 F10 cell lines compared with free drug alone and exhibited that SLNs drug delivery is suitable and effective drug against HepG2, MCF 7 and melanoma B16 F10 cell lines along with synergistic effect for

Table 9 Stability studies data of SLNs

\begin{tabular}{|c|c|c|c|c|c|c|}
\hline \multirow[t]{2}{*}{ Months } & \multicolumn{3}{|l|}{$4{ }^{\circ} \mathrm{C}$ refrigerated } & \multicolumn{3}{|l|}{ RT } \\
\hline & Particle size $(\mathrm{nm})^{*}$ & EE ATS $(\%)^{*}$ & EE VIN $(\%)^{*}$ & Particle size $(\mathrm{nm})^{*}$ & EE ATS $(\%)^{*}$ & EE VIN (\%)* \\
\hline 0 & $323 \pm 4$ & $64.69 \pm 0.6$ & $65.98 \pm 0.6$ & $323 \pm 6.3$ & $64.69 \pm 0.3$ & $65.98 \pm 0.5$ \\
\hline 1 & $329 \pm 7.3$ & $64.46 \pm 0.7$ & $65.75 \pm 1.6$ & $345 \pm 5.4$ & $64.28 \pm 1.1$ & $65.49 \pm 0.7$ \\
\hline 2 & $347 \pm 8.6$ & $64.28 \pm 1.2$ & $65.51 \pm 0.9$ & $392 \pm 6$ & $63.77 \pm 0.9$ & $64.82 \pm 1.1$ \\
\hline 3 & $354 \pm 5.4$ & $63.88 \pm 0.8$ & $65.16 \pm 1.3$ & $428 \pm 9.5$ & $62.92 \pm 1.6$ & $64.11 \pm 0.9$ \\
\hline 6 & $383 \pm 8.2$ & $62.49 \pm 0.6$ & $64.49 \pm 0.9$ & $797 \pm 15.4$ & $60.58 \pm 2.1$ & $62.15 \pm 1.6$ \\
\hline Mean & 347.2 & 63.96 & 64.51 & 457 & 63.25 & 65.38 \\
\hline
\end{tabular}

RT, room temperature

${ }^{*} p<0.05$ value is insignificant 
HepG2 cell line. The stability results showed that the formulation was stable up to 6 months under refrigerated conditions. This strategy of SLNs is promising and has the potential to improve the efficacy of ATS and VIN against cancer.

\section{Abbreviations}

ATS: Atorvastatin calcium; VIN: Vinpocetine; SLNs: Solid lipid nanoparticles; CPP: Critical process parameters; CQA: Critical quality attributes; \% EE: Percent entrapment efficiency; \% DL: Percent drug loading; TEM: Transmission electron microscopy; X-RD: X-ray diffraction; PDI: Poly dispersity index; ZP: Zeta potential; PBS: Phosphate-buffered saline; PS: Particle size; GMS: Glycerol monostearte; DRI: Dose reduction index; Cl: Combination index; Mg: Milligram; Gm: Gram.
\end{abstract}

\section{Acknowledgements}

We are thankful to University of Mumbai for Minor Research Project (MRP 457/2019-20). We are grateful to Suresh Kare Indoco Foundation for awarding the fellowship for the research work. We are thankful to ACTREC, Tata Memorial Center Navi Mumbai for providing the facility for Cancer Cell line Study.

\section{Authors' contributions}

Conceptualization, investigation, and writing RRL and ASS; methodology, validation, and data analysis RRL and ASS, experimental performance ASS All authors have critically reviewed and approved the final submission of the manuscript. All authors read and approved the final manuscript.

\section{Funding}

Mumbai University Minor Research Project (MRP 457/2019-20) grant received.

\section{Availability of data and materials}

The data generated or analyzed during this study are included in this article, if any excess data is required, it will be available from the corresponding author on reasonable request.

\section{Declarations}

Ethics approval and consent to participate Not applicable.

\section{Consent for publication}

Not applicable.

\section{Competing interests}

The authors declare no competing of interests.

Received: 21 April 2021 Accepted: 29 September 2021

Published online: 15 October 2021

\section{References}

1. Ali H, Shirode AB, Sylvester PW, Nazzal S (2010) Preparation, characterization, and anticancer effects of simvastatin-tocotrienol lipid nanoparticles. Int J Pharm 389(1-2):223-231. https://doi.org/10.1016/j.jpharm.2010.01. 018

2. Gazzerro P, Proto MC, Gangemi G, Malfitano AM, Ciaglia E, Pisanti S, Santoro A, Laezza C, Bifulco M (2012) Pharmacological actions of statins: a critical appraisal in the management of cancer. Pharmacol Rev 64(1):102-146. https://doi.org/10.1124/pr.111.004994

3. Pisanti S, Picardi P, Ciaglia E, D’Alessandro A, Bifulco M (2014) Novel prospects of statins as therapeutic agents in cancer. Pharmacol Res 88:84-98. https://doi.org/10.1016/.jphrs.2014.06.013

4. Huang EW, Xue SJ, Zhang Z, Zhou JG, Guan YY, Tang YB (2012) Vinpocetine inhibits breast cancer cells growth in vitro and in vivo. Apoptosis 17(10):1120-1130. https://doi.org/10.1007/s10495-012-0743-0
5. Parhi P, Mohanty C, Sahoo SK (2012) Nanotechnology-based combinational drug delivery: an emerging approach for cancer therapy. Drug Discov Today 17(17-18):1044-1052. https://doi.org/10.1016/j.drudis.2012. 05.010

6. Bhushan S, Kakkar V, Pal HC, Guru SK, Kumar A, Mondhe D, Sharma PR, Taneja SC, Kaur IP, Singh J, Saxena AK (2012) Enhanced anticancer potential of encapsulated solid lipid nanoparticles of TPD: a novel triterpenediol from Boswellia serrate. Mol Pharmaceutics 10:225-235. https://doi. org/10.1021/mp300385m

7. Lala RR, Shinde AS, Nandvikar NY (2018) Solid lipid nanoparticles: a promising approach for combinational drug therapy in cancer. Int J Appl Pharm 10(5):17-22. https://doi.org/10.22159/ijap.2018v10i5.27894

8. Shah B, Khunt D, Bhatt H, Misra M, Padh H (2015) Application of quality by design approach for intranasal delivery of rivastigmine loaded solid lipid nanoparticles: effect on formulation and characterization parameters. Eur J Pharm Sci 78:54-66. https://doi.org/10.1016/j.ejps.2015.07.002

9. Rangaraj N, Pailla SR, Shah S, Prajapati S, Sampathi S (2020) QbD aided development of ibrutinib-loaded nanostructured lipid carriers aimed for lymphatic targeting: evaluation using chylomicron flow blocking approach. Drug Deliv Transl Res 10(5):1476-1494. https://doi.org/10. 1007/s13346-020-00803-7

10. Collisson EA, Kleer C, Wu M, De A, Gambhir SS, Merajver SD, Kolodney MS (2003) Atorvastatin prevents RhoC isoprenylation, invasion, and metastasis in human melanoma cells. Mol Cancer Ther 2:941-948

11. Cafforio P, Dammacco F, Gernone A, Silvestris F (2005) Statins activate the mitochondrial pathway of apoptosis in human lymphoblasts and myeloma cells. Carcinogenesis 26:883-891. https://doi.org/10.1093/ carcin/bgi036

12. Yang Z, Xiao H, Jin H, Koo PT, Tsang D, Yang CS (2010) Synergistic actions of atorvastatin with $\gamma$-tocotrienol and celecoxib against human colon cancer HT29 and HCT116 cells. Int J Cancer 126:852-863. https://doi.org/ 10.1002/ijc.24766

13. Mistafa O, Stenius U (2009) Statins inhibit Akt/PKB signaling via P2X7 receptor in pancreatic cancer cells. Biochem Pharmacol 78:1115-1126. https://doi.org/10.1016/.bcp.2009.06.016

14. Lau YY, Okochi H, Huang Y, Benet LZ (2006) Pharmacokinetics of atorvastatin and its hydroxy metabolites in rats and the effects of concomitant rifampicin single doses: relevance of first-pass effect from hepatic uptake transporters, and intestinal and hepatic metabolism. Drug Metab Dispos 34:1175-1181. https://doi.org/10.1124/dmd.105.009076

15. Bonoczk P, Gulyas B, Adam-Vizi V, Nemes A, Karpati E, Kiss B, Kapas M, Szantay C, Koncz I, Zelles T, Vas A (2000) Role of sodium channel inhibition in neuroprotection: effect of vinpocetine. Brain Res Bull 53:245-254. https://doi.org/10.1016/S0361-9230(00)00354-3

16. Tran TH, Choi JY, Ramasamy T, Truong DH, Nguyen CN, Choi HG, Yong CS, Kim JO (2014) Hyaluronic acid-coated solid lipid nanoparticles for targeted delivery of vorinostat to CD44 overexpressing cancer cells. Carbohydr Polym 114:407-415. https://doi.org/10.1016/j.carbpol.2014.08. 026

17. Banerjee S, Roy S, Bhaumik KN, Pillai I (2019) Mechanisms of the effectiveness of lipid nanoparticle formulations loaded with anti- tubercular drugs combinations toward overcoming drug bioavailability in tuberculosis. J Drug Target. https://doi.org/10.1080/1061186X.2019.1613409

18. Vichai V, Kirtikara K (2006) Sulforhodamine B colorimetric assay for cytotoxicity screening. Nat Protocol 1:1112-1116. https://doi.org/10.1038/ nprot.2006.179

19. Skehan P, Storeng R, Scudiero D, Monks A, McMahon J, Vistica D (1990) New colorimetric cytotoxicity assay for anticancer-drug screening. J Natl Cancer Inst 82:1107-1112. https://doi.org/10.1093/jnci/82.13.1107

20. Li S, Wang L, Li N, Liu Y, Su H (2017) Combination lung cancer chemotherapy: design of a PH-sensitive transferrin-PEG-Hz-lipid conjugate for the co-delivery of docetaxel and baicalin. Biomed Pharmacother 95(27):548-555. https://doi.org/10.1016/j.biopha.2017.08.090

21. Rajpoot K, Jain SK (2018) Colorectal cancer-targeted delivery of oxaliplatin via folic acid-grafted solid lipid nanoparticles: preparation, optimization, and in vitro evaluation. Artif Cells Nanomed Biotechnol 46(6):1236-1247. https://doi.org/10.1080/21691401.2017.1366338

22. Das S, Ng WK, Tan RBH (2012) Are nanostructured lipid carriers (NLCs) better than solid lipid nanoparticles (SLNs): development, characterizations 
and comparative evaluations of clotrimazole-loaded SLNs and NLCs? Eur J Pharm Sci 47(1):139-151. https://doi.org/10.1016/j.ejps.2012.05.010

23. Aoki M, Ring TA, Haggerty JS (1987) Analysis and modeling of the ultrasonic dispersion technique. Adv Ceram Mater 2:209-212. https://doi.org/ 10.1111/j.1551-2916.1987.tb00082.x

24. Gidwani B, Vyas A (2016) Preparation, characterization, and optimization of altretamine loaded solid lipid nanoparticles using Box-Behnken design and response surface methodology. Artif Cells Nanomed Biotechnol 44:571-580. https://doi.org/10.3109/21691401.2014.971462

25. Shah KA, Date AA, Joshi MD, Patravale VB (2007) Solid lipid nanoparticles (SLN) of tretinoin: potential in topical delivery. Int J Pharm 345:163-171. https://doi.org/10.1016/j.ejps.2015.07.002

26. Subedi RK, Kang KW, Choi HK (2009) Preparation and characterization of solid lipid nanoparticles loaded with doxorubicin. Eur J Pharm Sci 37(3-4):508-513. https://doi.org/10.1016/j.ejps.2009.04.008

27. Gurumukhi VC, Bari SB (2020) Fabrication of efavirenz loaded nanoformulation using quality by design (QbD) based approach : exploring characterizations and in vivo safety. J Drug Deliv Sci Technol 56:101545. https://doi.org/10.1016/j.jddst.2020.101545

28. Liu J, Gong T, Wang C, Zhong Z, Zhang Z (2007) Solid lipid nanoparticles loaded with insulin by sodium cholate-phosphatidylcholine mixed micelles: preparation and characterization. Int J Pharm 340:153-162. https://doi.org/10.1016/j.jpharm.2007.03.009

29. Das S, Chaudhury A (2011) Recent advances in lipid nanoparticle formulations with solid matrix for oral drug delivery. AAPS Pharm SciTech 12:62-76. https://doi.org/10.1208/s12249-010-9563-0

30. Freitas C, Muller RH (1998) Spray-drying of solid lipid nanoparticles. Eur J Pharm Biopharm 46:145-151. https://doi.org/10.1016/S0939-6411(97) 00172-0
31. Chen H, Chang X, Du D, Liu W, Liu J, Weng T, Yang Y, Xu H, Yang X (2006) Podophyllotoxin-loaded solid lipid nanoparticles for epidermal targeting. J Control Release 110:296-306. https://doi.org/10.1016/j.jconrel.2005.09. 052

32. Gaspar DP, Fariav V, Goncalves LM, Taboda P, Lopez CR, Almeida AJ (2016) Rifabutin-loaded solid lipid nanoparticles for inhaled antitubercular therapy: physicochemical and in vitro studies. Int J Pharm 497:199-209. https://doi.org/10.1016/j.ijpharm.2015.11.050

33. Wang J, Zhou Y, Guo S, Wang Y, Wang H, Wang J, Zhao Y, Li X, Chen X (2017) Cetuximab conjugated and doxorubicin loaded silica nanoparticles for tumor-targeting and tumor microenvironment responsive binary drug delivery of liver cancer therapy. Mater Sci Eng C 76:944-950. https:// doi.org/10.1016/j.msec.2017.03.131

34. Fundaro A, Cavalli R, Bargoni A, Vighetto D, Zara GP, Gasco MR (2000) Non-stealth and stealth solid lipid nanoparticles (SLN) carrying doxorubicin: pharmacokinetics and tissue distribution after i.v. administration to rats. Pharmacol Res 42:337-343. https://doi.org/10.1006/phrs.2000.0695

35. Serpe L, Catalano MG, Cavalli R, Ugazio E, Bosco O, Canaparo R, Muntoni E, Frairia R, Gasco MR, Eandi M, Zara GP (2004) Cytotoxicity of anticancer drugs incorporated in solid lipid nanoparticles on HT-29 colorectal cancer cell line. Eur J Pharm Biopharm 58(3):673-680

\section{Publisher's Note}

Springer Nature remains neutral with regard to jurisdictional claims in published maps and institutional affiliations.

\section{Submit your manuscript to a SpringerOpen ${ }^{\circ}$ journal and benefit from:}

- Convenient online submission

- Rigorous peer review

- Open access: articles freely available online

- High visibility within the field

- Retaining the copyright to your article

Submit your next manuscript at $\boldsymbol{\nabla}$ springeropen.com 